\title{
VALOR ECONÔMICO DAS PRÁTICAS DE CONSERVAÇÃO DO SOLO NO ESTADO DE MINAS GERAIS EM 2006
}

\author{
Samuel Alex Coelho Campos* \\ Marcelo Dias Paes Ferreira* \\ Alexandre Bragança Coelho***
}

RESUMO: Este estudo buscou medir a importância econômica das práticas de conservação do solo, das matas e diversas questões estruturais dos estabelecimentos agropecuários mineiros utilizando o método dos preços hedônicos espaciais. Os resultados confirmam a importância das práticas de conservação, destacando a utilização de terraços que elevam o preço da terra. Contudo, a utilização de rotação de culturas apresentou relação negativa com o preço da terra. Destaca-se também a relação inversa entre áreas de reserva legal e o preço da terra, o que pode ser interpretado como um custo de oportunidade da área ocupada com matas.

PALAVRAS-CHAVE: Meio ambiente; Minas Gerais; Preços hedônicos espaciais.

\section{ECONOMIC VALUE OF PRACTICES IN SOIL CONSERVATION IN THE STATE OF MINAS GERAIS IN 2006}

\begin{abstract}
The economic importance of practices of soil conservation, forests and several structural issues of agro-livestock establishments in the state of Minas Gerais, Brazil, was measured by employing spatial hedonic price method. Results confirm the importance of conservation practices with special reference to terraces that increase land price. The use of crop rotation had a negative relationship with land price. Inverse relationship between legal reserve areas and land price is underscored. The above may be interpreted as the cost of the opportunity of forest areas.
\end{abstract}

KEY WORDS: Environment; Minas Gerais; Spatial hedonic prices.

\footnotetext{
"Doutor em Ciências (Economia Aplicada) pela Escola Superior de Agricultura "Luiz de Queiroz"/USP. Docente no Instituto de Ciências da Sociedade e Desenvolvimento Regional - Universidade Federal Fluminense, Brasil. E-mail: s.alex.coelho@gmail.com

** Doutor em Economia Aplicada pelo Departamento de Economia Rural da Universidade Federal de Viçosa. Docente Adjunto da Escola de Agronomia/Universidade Federal de Goiás, Brasil.

***: Doutor em Economia Aplicada pela Universidade Federal de Viçosa. Bolsista de Produtividade em Pesquisa do CNPq. Docente Associado do Departamento de Economia Rural da Universidade Federal de Viçosa, Viçosa, $\mathrm{MG}$, Brasil.
} 


\section{INTRODUÇÃO}

A atividade agropecuária utiliza um vasto conjunto de insumos, dentre os quais se destacam aqueles relacionados ao meio ambiente e aos recursos naturais, tal como os recursos hídricos e o solo, sendo que a capacidade produtiva da terra, e, consequentemente, o desempenho econômico da atividade agropecuária, está diretamente relacionado à disponibilidade e qualidade desses recursos.

Dessa forma, pode ser atribuído às características do solo a sua capacidade produtiva, sendo que essas características podem ser refletidas no preço da terra. Assim, se o mercado de terra funciona perfeitamente, seu preço será dado pela capacidade produtiva (MADDISON, 2000; TÜRKER; ÖZTÜRK; PAK, 2003).

Além das características do solo e da disponibilidade dos recursos hídricos, o valor da terra está relacionado às melhorias na propriedade, à localização, a atributos ambientais, etc., que influenciam a sua capacidade produtiva e/ou sua capacidade de gerar renda (PALMQUIST; DANIELSON, 1989; LE GOFFE, 2000; MCCONNELL; WALLS, 2005; LICHTENBERG et al., 2010). O solo pode ser utilizado para outras atividades não agropecuárias e, ou não produtivas e não comercializáveis, como a conservação de florestas e matas que geram benefícios sociais. Entretanto, a manutenção de áreas com florestas apresenta tanto um custo de oportunidade ao produtor, dado pelas receitas que poderiam ser obtidas com a exploração comercial desta área, como também um investimento para a manutenção da capacidade produtiva da propriedade, por meio da conservação dos insumos ambientais e da qualidade do solo (LE GOFFE, 2000).

Essa preocupação quanto à conservação do meio ambiente está presente na legislação brasileira por meio do código florestal, que impõe a manutenção de áreas com florestas nas propriedades rurais, bem como todos os custos e encargos sobre os proprietários. Tal legislação limita o direito de propriedade, restringindo o uso da terra em favor do interesse comum da sociedade e desconsiderando aspectos econômicos (RIGONATTO, 2006). Assim, se por um lado, a manutenção das matas e florestas é importante para a conservação dos recursos ambientais, permitindo conservação da capacidade produtiva, também gera benefícios para a sociedade, que pode desfrutar da paisagem cênica e outros benéficos, mas o custo de manter a área 
não utilizada para a produção agropecuária e geração de renda é arcado apenas pelo produtor rural (LE GOFFE, 2000; TÜRKER; ÖZTÜRK; PAK, 2003).

As práticas de conservação do solo (terraços, plantio direto, rotação de culturas, etc) também estão diretamente relacionadas com o preço das áreas agrícolas, uma vez que permitem a manutenção da produtividade e da qualidade da terra para a agropecuária (PALMQUIST; DANIELSON, 1989).

Alguns estudos trataram do tema da preservação ambiental e seus impactos econômicos sobre a atividade agropecuária. McConnell (1983) analisou os aspectos econômicos de conservação do solo e concluiu que: (i) a elevação da degradação do solo não implica em desconhecimento de seus efeitos sobre a produtividade pelo produtor, pelo contrário, deve haver um dado nível ótimo econômico de degradação do solo, dependente da taxa de retorno da economia; e (ii) os produtores conservarão o solo se estes tomarem conhecimento que a erosão do solo afetará negativamente o valor de revenda da terra.

A relação entre valor da terra e erosão foi, posteriormente, analisada por Palmquist e Danielson (1989), constatando que os produtores são incentivados economicamente a utilizar práticas agrícolas de controle da erosão, uma vez que estas protegeriam a produtividade e o valor da terra. Le Goffe (2000) buscou identificar e monetizar alguns dos efeitos externos da agricultura e silvicultura francesa, no sentido de identificar a propensão a pagar pela melhoria do meio ambiente, concluindo que as áreas com pastagens apresentam associação positiva ao preço da terra, enquanto áreas de matas apresentaram associação negativa. Ao estudar a relação entre o valor da terra agrícola e variáveis ambientais e estruturais das propriedades na Inglaterra e País de Gales, Maddison (2000) concluiu que a maior parte das variáveis ambientais se mostrou positivamente relacionada ao preço da terra.

Alguns destes estudos (PALMQUIST; DANIELSON, 1989; LE GOFFE, 2000; MADDISON, 2000) utilizaram modelos de preços hedônicos para valoração ambiental, mas não consideraram problemas graves como a omissão de variáveis e autocorrelação espacial dos erros. O segundo problema pode ocorrer pela omissão de variáveis ambientais correlacionadas espacialmente como a qualidade do solo, clima, entre outros, uma vez que vários produtores estão sujeitos a condições 
climáticas semelhantes que influenciam sua capacidade produtiva externamente e apresentam dificuldades quanto a obtenção de variáveis que possam retratar essas características (LEGGETT; BOCKSTAEL, 2000; MALLIOS et al., 2009). A importância deste problema reside no fato de que, havendo omissão de variáveis e autocorrelação espacial, os parâmetros estimados serão inconsistentes (MC CONNELL; WALLS, 2005).

Desta forma, dada a importância econômica da agropecuária para o Estado de Minas Gerais, do solo para esta atividade, além de questões relacionadas aos custos da legislação para o produtor, pergunta-se: Qual a contribuição econômica das práticas de conservação do solo e das florestas para a manutenção da qualidade ambiental dos recursos ambientais e produtividade agropecuária nos municípios mineiros? Sendo assim, este trabalho estabelece uma associação entre o preço das propriedades rurais, atributos ambientais e práticas de conservação e, especificamente, determina a contribuição econômica de cada uma destas variáveis.

Este artigo está dividido em três seções além desta. Na segunda seção são apresentados os procedimentos metodológicos, como modelos, variáveis utilizadas e fonte de dados. Na terceira seção os resultados obtidos são apresentados e discutidos. Posteriormente, as conclusões, limitações e sugestões para pesquisas futuras são apresentadas na quarta seção.

\section{MATERIAL E MÉTODOS}

Como descrito anteriormente, o valor das terras pode ser atribuído a diversas características e serviços fornecidos por essa. Desta forma, o modelo de preços hedônicos foi utilizado, uma vez que este relaciona o preço de um dado bem às suas diversas características e, posteriormente, o modelo foi analisado quanto à presença da correlação espacial.

\subsection{MODELO ESPACIAL DE PREÇOS HEDÔNICOS}

A terra possui diversos atributos que influenciam sua procura pelos 
produtores rurais para a produção agropecuária. Alguns, como qualidade do solo e clima, não podem ser modificados, enquanto outros atributos, como benfeitorias, podem. O preço da terra é funcionalmente dependente destas características (MADDISON, 2000). Dessa forma, pode-se utilizar o método de preços hedônicos para identificar os preços implícitos para cada atributo, que são revelados pelos agentes econômicos por meio dos diferentes preços observados para os produtos, conforme seus atributos são modificados (ROSEN, 1974).

O modelo de preços hedônicos pode ser representado, em sua forma geral:

$$
p=X \beta+\varepsilon,
$$

em que " $p$ " é o vetor dos preços da terra por hectare para cada município mineiro, "X" é a matriz de variáveis explanatórias relacionadas ao preço da terra (variáveis estruturais, locacionais e práticas de conservação) $\mathrm{e}$ " $\varepsilon$ " o vetor do termo de erro. Os parâmetros estimados, representados por $\beta$ em (1), são interpretados como o preço marginal para cada característica, obtido por meio da derivada parcial da função (1) para cada característica analisada, permitindo valorar monetariamente a relação entre os atributos e o valor da terra (ANSELIN; LOZANO-GRACIA, 2008). Se a primeira derivada parcial em relação a um dado atributo apresentar sinal positivo (negativo), esse atributo está relacionado a um aumento (diminuição) do valor da propriedade.

Os preços implícitos obtidos pela equação de preços hedônicos são preços de equilíbrio, não podendo ser interpretados como características da demanda ou da oferta. Esses preços representam a interação de ambas as forças de mercado (CRAIG; PALMQUIST; WEISS, 1998). Entretanto, a oferta de terra em Minas Gerais pode ser considerada inelástica e fixa, uma vez que não há fronteiras agrícolas a serem incorporadas ao processo produtivo. Assim, as variações nos preços seriam provenientes de deslocamentos da curva de demanda. Nesse sentido, a variação na quantidade dos atributos relacionados à terra atua como deslocador da demanda por terra, modificando seu preço. Se essa variação afetar apenas algumas áreas, seus proprietários terão ganhos de capital (PALMQUIST; DANIELSON, 1989).

A teoria econômica não especifica regras para a forma funcional descrita pela 
equação (1) (MCCONNELL; WALLS, 2005), entretanto, Cropper, Deck e Mcconnell (1988), por meio de simulações, mostraram que quando variáveis importantes são omitidas ou substituídas por proxies, formas funcionais como a linear são superiores a outras mais complexas, como a transformação de Box-Cox.

Entretanto, como apresentado anteriormente, as características das propriedades podem ser influenciadas pela sua distribuição espacial, o que implicará que o preço da terra não dependerá apenas de suas características individuais, mas também das características da terra dos municípios vizinhos (MALLIOS et al., 2009). Como resultado, o método dos Mínimos Quadrados Ordinários não é adequado, devendo ser utilizados modelos de econometria espacial, que incorporam esta distribuição na estimação dos parâmetros.

A dependência espacial pode ser incorporada ao modelo por meio de defasagens da variável dependente (2) ou por meio do termo do erro (3).

$$
\begin{aligned}
& p=\gamma W p+X \beta+\mu, \\
& \mu=\rho W \mu+e,
\end{aligned}
$$

em que " $p$ ", " $X$ " e "e" são definidos como em (1); $\gamma$ é o parâmetro de autocorrelação espacial; " $W$ " é a matriz de pesos espaciais padronizados; o produto "Wp" é variável dependente espacialmente defasada; $\rho$ é o coeficiente dos erros espaciais correlacionados; e "Wu" é o termo do erro espacialmente defasado.

\subsection{VARIÁVEIS E TRATAMENTO DOS DADOS}

Os dados utilizados foram obtidos do Censo Agropecuário de 2006 e correspondem a todos municípios mineiros, tendo como período de referência o ano de 2006 ( $1^{\circ}$ de janeiro a 31 de dezembro) e como data de referência 31 de dezembro de 2006 (compreendendo o ano civil). Os mapas para a estimação espacial foram obtidos junto ao MMA (2010) e GeoMINAS (2010). A densidade populacional foi calculada utilizando dados do Censo Demográfico de 2010 (número de habitantes do município) e dados do site Cidades@ (área da unidade municipal), ambos disponibilizados pelo Instituto Brasileiro de Geografia e Estatística. Na estimação 
dos efeitos marginais foram utilizados os pacotes estatísticos spdep (BIVAND, 2010) e sphet (PIRAS, 2010a) aplicados ao programa estatístico R, versão 2.12.1, e GeoDa, versão 0.9.5-i5.

As variáveis utilizadas estão descritas em relação à área total dos estabelecimentos, em hectares (AE), ou em relação ao número total de estabelecimentos (NE). Foram utilizadas as seguintes variáveis:

- Valor da terra - Valor da terra dos estabelecimentos agropecuários (inclusive matas naturais), por município, em mil Reais/hectare, incluindo a área com matas naturais. Esse valor foi obtido diretamente do Censo Agropecuário de 2006 por meio da variável: valor dos bens dos estabelecimentos em 31/12: bens imóveis - terras (inclusive matas naturais);

- Plantio em nível - Área total dos estabelecimentos agrícolas que plantam em nível, em ha/área total dos estabelecimentos, em ha/AE;

- Terraços - Área total dos estabelecimentos agrícolas que utilizam terraços, em ha/AE;

- Rotação - Área total dos estabelecimentos cultivada em sistema de rotação de culturas, em há/AE;

- Renovação - Área total dos estabelecimentos utilizada com lavouras para reforma e, ou renovação e, ou recuperação de pastagens, em ha/AE;

- Pousio - Área total dos estabelecimentos utilizada em pousio ou descanso do solo, em ha/AE;

- Proteção - Área total dos estabelecimentos destinada à proteção e, ou conservação de encostas, em ha/AE;

- Preservação - Área dos estabelecimentos agrícolas com matas e, ou florestas naturais destinadas à preservação permanente ou reserva legal, em ha/AE;

- Preservação 2 - Área dos estabelecimentos agrícolas com matas e, ou florestas naturais destinadas à preservação permanente ou reserva legal, 
em ha/AE, elevado ao quadrado;

- Matas - Área dos estabelecimentos agrícolas com matas e, ou florestas naturais (exclusive área de preservação permanente e em sistemas agroflorestais), em ha/AE;

- Matas 2 - Área dos estabelecimentos agrícolas com matas e, ou florestas naturais (exclusive área de preservação permanente e em sistemas agroflorestais), em ha/AE, elevado ao quadrado;

- Florestais - Área dos estabelecimentos agrícolas com matas e, ou florestas plantadas com essências florestais, em ha/AE;

- Florestais 2 - Área dos estabelecimentos agrícolas com matas e, ou florestas plantadas com essências florestais, em ha/AE, elevado ao quadrado;

- Pastagens - Área dos estabelecimentos agropecuários com pastagens degradadas, em hectares/AE;

- Degradadas - Áreas degradadas, salinizadas, erodidas e desertificadas, em hectares/AE;

- Tratores - Número de tratores, em unidades/AE;

- Financiamento - Somatório do valor dos valores obtidos pelos estabelecimentos agropecuários de programas de crédito do governo em Reais/AE;

- Área - Área média dos estabelecimentos agropecuários, em hectares;

- Hídrico - Número de estabelecimentos agropecuários com nascentes, rios, riachos ou lagos, não protegidos por matas/NE;

- Permanente - Área dos estabelecimentos plantada com lavouras permanentes (culturas de longa duração, tais como: café, laranja, cacau, banana, uva, etc. que, após a colheita, não necessitasse de novo plantio, produzindo por vários anos consecutivos), em hectares/AE;

- Temporária - Área dos estabelecimentos plantada com lavouras temporárias (culturas de curta duração, geralmente inferior a um ano, 
e que só produzem uma vez, pois na colheita destrói-se a planta), em hectares/AE;

- Forrageiras - Área dos estabelecimentos plantada com forrageiras para corte e alimentação de animais, em hectares, AE; e

- Demografia - Número de pessoas por quilometro quadrado.

Desta forma, foram incorporadas variáveis passíveis de modificação pelos produtores, como práticas de conservação do solo (plantio em nível, utilização de terrações, etc.) e áreas degradadas, e os recursos naturais disponíveis, como recursos hídricos, etc, como tratado em Palmquist e Danielson (1989), de forma a determinar os preços implícitos dessas.

As variáveis lineares e quadráticas para as áreas com matas e reservas legais foram incluídas de forma a captar o trade-off entre estas e o valor da terra, e indiretamente, seu custo de oportunidade e seus efeitos sobre a produtividade agrícola, conforme abordado por Le Goffe (2000) e Türker, Öztürk e Pak (2003). Por meio destas variáveis formula-se a hipótese que, se a área ocupada com matas e florestas apresentar relação negativa com o valor da terra, haverá um excesso de área destinada à conservação ambiental que o efetivamente necessário, ambiental e economicamente, e, se apresentar relação positiva, haverá escassez de área para a conservação ambiental.

Além das variáveis relacionadas às práticas de conservação adotadas e características dos estabelecimentos agropecuários, foram utilizadas outras variáveis como forma de evitar vieses por omissão de variáveis. A variável "Tratores", utilizada como proxy para a área agricultável dos estabelecimentos, busca sua relação para com o valor da terra. A variável "Financiamento" foi adicionada buscando captar imperfeições do mercado relacionadas ao valor da terra, uma vez que estes benefícios são incorporados ao valor da terra, entre os quais o acesso ao crédito subsidiado pelo governo e garantia de empréstimos (DE JANVRY et al., 2001).

Avariável “Área”, referente àárea média dos estabelecimentos, foi incorporada à análise de forma a contornar problemas com custos de transações. Se há custos de transação, propriedades de diferentes tamanhos, que teriam valores idênticos por hectare, por exemplo, podem ser vendidas por menores valores por hectare, 
por exemplo, do que maiores propriedades, que alcançariam maiores valores por hectare (MADDISON, 2000). A variável "Hídrico" foi incorporada à análise uma vez que a produção agropecuária é altamente depende da disponibilidade de recursos hídricos.

As variáveis "Permanente", "Temporária" e "Forrageiras" foram incorporadas como estratégia para contornar a limitação de inexistência de indicadores ecológicos apropriados para mensurar as externalidades da produção agropecuária, procedimento também adotando por Le Goffe (2000), bem como captar o efeito de áreas já estabelecidas sobre o preço da terra agrícola.

A variável "Demografia" foi adicionada para contornar os efeitos da concentração populacional do município sobre o valor das terras e também como variável proxy para a proximidade do mercado consumidor e lucro potencial, além de amenidades como distância à escola ou existência de mercado de trabalho não agrícola (CRAIG; PALMQUIST; WEISS, 1998; MADDISON, 2000).

\section{RESULTADOS E DISCUSSÃO}

Como apontado anteriormente, os estudos que utilizaram modelos de preços hedônicos na determinação dos preços implícitos de diversos atributos podem estar incorrendo em vieses pela própria relação espacial das variáveis ou por omissão de variáveis que adicionam autocorrrelação espacial aos erros. Buscando superar estas limitações e estimar parâmetros consistentes testou-se a presença de autocorrelação espacial.

Inicialmente, testou-se a existência de dependência espacial dos erros utilizando o teste I de Moran. O valor da estatística foi I = 5,34, que permitiu rejeitar a hipótese nula de que os erros não apresentavam autocorreção serial. Dessa forma, se os parâmetros fossem estimados por Mínimos Quadrados Ordinários, as estimativas seriam viesadas. Esse resultado já era esperado pela relação das características ambientais relacionadas ao valor da propriedade, geralmente distribuídas de forma espacial.

Uma vez que o modelo deve considerar a autocorreção espacial, 
determinou-se como essa relação espacial deve ser modelada, como defasagem da variável dependente (2) ou como defasagem do erro (3). Para isto, utilizou-se, como apresentado por Florax et al. (2003), o teste do Multiplicador de Lagrange (LM), sendo que deve ser estimado o modelo que apresentar o maior valor significativo para este teste em sua versão robusta. Os valores para a o teste LM robusto para defasagem da variável dependente e do erro foram 6,07 e 8,30, respectivamente, sendo ambos significativos ao nível de significância de 1\%. Assim, os testes indicam que o modelo mais adequado deve considerar a defasagem do erro.

Entretanto, as unidades espaciais podem diferir em diversas características, o que pode resultar em heterocedasticidade e, desta forma, o método dos Mínimos Quadrados Ordinários não será o melhor estimador linear não viesado. Desta forma, foi utilizado o teste de Breusch e Pagan (1979). Segundo este teste, o modelo espacial do erro apresentou heterocedasticidade ao nível de significância de $10 \%\left(\chi_{22}^{2} \mathrm{gl}\right.$ $=180,36)$. Para contornar este problema, foi estimado o modelo de erro espacial pelo Método Generalizado dos Momentos (MGM), proposto por Kelejian e Pruncha (2010), método robusto quanto à variância do erro para o modelo da defasagem do erro. $\mathrm{O}$ modelo também foi testado quanto à multicolinearidade utilizando o Fator de Inflação da Variância, obtendo o valor de 3,59, não caracterizando, desta forma, um problema para as estimações, segundo Gujarati (2006).

As estimativas (Tabela 1) indicaram que, de forma geral, as variáveis apresentaram sinais esperados, embora muitas estimativas tenham sido não significativas a $10 \%$. O parâmetro "rho" para a defasagem do erro foi significativo a $1 \%$, indicando a validade da especificação do modelo e que, estatisticamente, há características espaciais importantes que são desconsideradas pelos Mínimos Quadrados Ordinários.

A maior parte das variáveis relacionadas às técnicas de conservação do solo apresentou sinais esperados, embora apenas "Terraços", "Renovação" e "Pousio" tenham sido significativas ao nível de $5 \%$. A utilização de terraços para o controle da erosão relaciona-se positivamente ao preço da terra, de forma que um aumento em um ponto percentual na área com terraços $(0,01)$ eleva o valor da terra em aproximadamente $\mathrm{R} \$ 25,00 / \mathrm{ha}$.

A não significância da prática de rotação de culturas pode ser atribuída 
à qualidade da rotação, uma vez que esta prática carece de planejamento acerca das culturas a serem utilizadas na rotação, de forma a efetivamente contribuir para a restauração da matéria orgânica e dos nutrientes do solo, demandando conhecimentos ou assistência técnica que muitos produtores podem não dispor.

Tabela 1. Estimativas para o modelo de preços hedônicos do valor da terra

\begin{tabular}{lcccc}
\hline Variável & Coeficiente & Erro Padrão & Estatísticat & Probabilidade \\
\hline Constante & 2.92 & 0.55 & 5.33 & $0.00^{* *}$ \\
Plantio em nível & 0.04 & 0.40 & 0.09 & 0.93 \\
Terraços & 2.48 & 0.96 & 2.58 & $0.01^{* *}$ \\
Rotação & 0.39 & 0.71 & 0.56 & 0.58 \\
Renovação & -1.60 & 0.72 & -2.23 & $0.03^{*}$ \\
Pousio & -1.52 & 0.77 & -1.98 & $0.05^{*}$ \\
Proteção & 0.80 & 0.60 & 1.32 & 0.19 \\
Preservação & 0.20 & 3.30 & 0.06 & 0.95 \\
Preservação 2 & 0.16 & 9.14 & 0.02 & 0.99 \\
Matas & -15.58 & 2.51 & -6.21 & $0.00^{* *}$ \\
Matas 2 & 29.60 & 6.98 & 4.24 & $0.00^{* *}$ \\
Florestais & -0.73 & 3.53 & -0.21 & 0.84 \\
Florestais 2 & 11.95 & 9.94 & 1.20 & 0.23 \\
Pastagens & -2.17 & 2.35 & -0.92 & 0.36 \\
Degradadas & -27.20 & 13.88 & -1.96 & $0.05^{*}$ \\
Tratores & 397.43 & 41.57 & 9.56 & $0.00^{* *}$ \\
Financiamento & 1.80 & 1.25 & 1.44 & 0.15 \\
Área & $-3.71 \mathrm{E}-03$ & $1.34 \mathrm{E}-03$ & -2.76 & $0.01 * *$ \\
Hídrico & 1.44 & 0.60 & 2.38 & $0.02^{*}$ \\
Permanente & 8.81 & 1.20 & 7.34 & $0.00^{* *}$ \\
Temporária & 0.30 & 1.24 & 0.24 & 0.81 \\
Forrageiras & 0.07 & 1.67 & 0.04 & 0.97 \\
Demografia & $3.03 \mathrm{E}-03$ & $5.67 \mathrm{E}-04$ & 5.34 & $0.00^{* *}$ \\
Rho & 0.34 & 0.08 & 4.25 & $0.00^{* *}$ \\
\hline Fonte: Resultados da Pesquisa. Observação: ** Indica que o parâmetro estimado é estatisticamente \\
significativo a 1\%; Indica que o parâmetro estimado é estatisticamente significativo a 5\%.
\end{tabular}


As áreas relativas de renovação e pousio apresentaram sinal negativo, sendo que o aumento em um ponto percentual na área de renovação e pousio $(0,01)$ reduziria, aproximadamente, em $\mathrm{R} \$ 16,00 /$ ha e $\mathrm{R} \$ 15,00 /$ ha, respectivamente, o preço da terra nos municípios de Minas Gerais. Essa relação pode ser explicada pelo fato que estas áreas enquanto estão em pousio ou sendo recuperadas ainda estão degradadas e possuem potencial produtivo comprometido. Ademais, áreas em descanso ou recuperação não estão inseridas no processo produtivo, o que reduz o seu preço, uma vez que o comprador deveria arcar com os custos de uma eventual limpeza e preparação do solo. As áreas "degradadas" afetaram negativamente o preço da terra, de forma que o aumento em um ponto percentual $(0,01)$ na área degrada dos municípios mineiros reduz em $\mathrm{R} \$ 272,00$ o preço por hectare da terra.

Tabela 2. Estatísticas descritivas das observações utilizadas na estimação

(Continua)

\begin{tabular}{lccccc}
\hline \multicolumn{1}{c}{ Variável } & Observações & Média & Desvio Padrão & Mínimo & Máximo \\
\hline Valor da Terra & 330 & 5,771 & 3,352 & 0,685 & 25,508 \\
Plantio em nível & 330 & 0,421 & 0,231 & 0,009 & 0,961 \\
Terraços & 330 & 0,076 & 0,095 & 0 & 0,590 \\
Rotação & 330 & 0,139 & 0,118 & 0 & 0,568 \\
Renovação & 330 & 0,131 & 0,118 & 0 & 0,758 \\
Pousio & 330 & 0,107 & 0,092 & 0 & 0,693 \\
Proteção & 330 & 0,189 & 0,163 & 0 & 0,901 \\
Preservação & 330 & 0,111 & 0,053 & 0,008 & 0,378 \\
Preservação 2 & 330 & 0,015 & 0,015 & 0 & 0,143 \\
Matas & 330 & 0,053 & 0,093 & 0 & 0,666 \\
Matas 2 & 330 & 0,011 & 0,040 & 0 & 0,444 \\
Florestais & 330 & 0,027 & 0,056 & 0 & 0,382 \\
Florestais 2 & 330 & 0,004 & 0,017 & 0 & 0,146 \\
Pastagens & 330 & 0,034 & 0,029 & 0 & 0,219 \\
Degradadas & 330 & 0,003 & 0,006 & 0 & 0,085 \\
Tratores & 330 & 0,004 & 0,004 & 0 & 0,021 \\
Financiamento & 330 & 0,056 & 0,157 & 0 & 2,704 \\
Área & 330 & 70,452 & 63,017 & 9,053 & 537,509 \\
\hline
\end{tabular}


(Conclusão)

\begin{tabular}{lccccc}
\hline \multicolumn{1}{c}{ Variável } & Observações & Média & Desvio Padrão & Mínimo & Máximo \\
\hline Hídrico & 330 & 0,813 & 0,130 & 0,178 & 0,992 \\
Permanente & 330 & 0,083 & 0,100 & 0,001 & 0,549 \\
Temporária & 330 & 0,082 & 0,073 & 0,005 & 0,580 \\
Forrageiras & 330 & 0,024 & 0,024 & 0 & 0,176 \\
Demografia & 330 & 37,104 & 50,695 & 2,327 & 398,643 \\
\hline
\end{tabular}

Fonte: Resultados da pesquisa.

Os coeficientes para "preservação" e "florestais" indicaram pela relação entre esses e o valor da terra em forma de "U", sendo que o ponto de mínimo para "preservação" seria alcançado com uma área de -62,5\%, que não é fisicamente possível. A relação entre a proporção da área ocupada com matas e, ou florestas plantadas com essências florestais teve como ponto de mínimo o valor de 0,0305, ou 3,05\% da área, que é um valor acima da média (Tabela 2). Contudo, ambas as variáveis foram não significativos a $10 \%$. Esse resultado pode ser explicado pelo fato dos municípios mineiros serem heterogêneos quanto ao relevo, conforme Carneiro, Fontes e Fontes (2005). Assim, esses atributos poderiam ser significativos naqueles municípios que apresentassem relevo mais acidentado e não significativos para os municípios de relevo não acidentado.

A variável "matas", que capta a área destinada à reserva legal determinada pela legislação brasileira apresentou sinal significativo, tanto no termo linear quanto no quadrático, apresentando uma relação em "U" com o preço da terra, sendo o ponto de mínimo 0,2631. Para proporções de áreas ocupadas nos estabelecimentos menores a essa, o aumento proporcional da área ocupada com matas reduz o valor da terra. À direita desse ponto, o aumento da área está relacionado a maiores valores da terra, chegando próximo a $R \$ 3$ mil por hectare (Figura 1 ). 


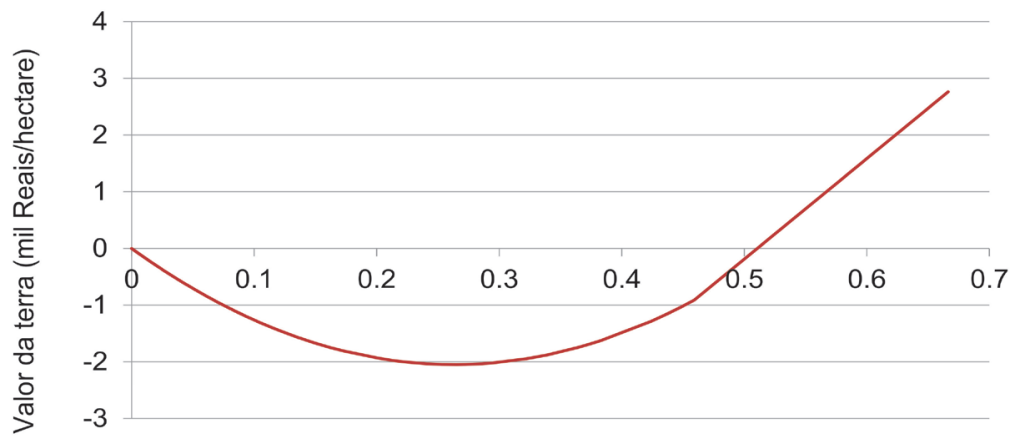

- Proporção das matas nos estabelecimentos agropecuários

Figura 1. Relação entre a proporção da área ocupada com matas e o valor da terra, em mil Reais por hectare.

Fonte: Resultados da pesquisa.

Ademais, observado o valor médio para proporção da área ocupada com matas e distribuição dessa proporção nos estabelecimentos

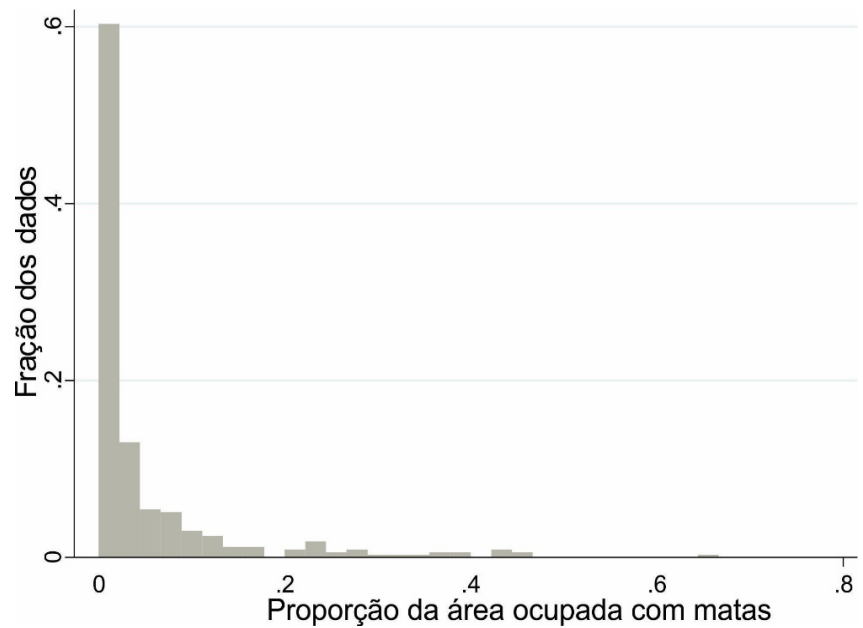

Figura 2. Distribuição da proporção da área ocupada com matas nos municípios Fonte: Resultados da pesquisa. 
Na Figura 2 se observa que a maior parte dos estabelecimentos possui uma área ocupada com matas inferior a $20 \%$ da área total, inferior ao ponto de inflexão. Esse resultado indica que pode ser dada menor atenção aos pontos à direita do ponto de mínimo e também que a presença de áreas ocupadas com matas está associada à redução do valor da terra em até $\mathrm{R} \$-2.050,13$ no ponto de mínimo.

Essa relação negativa pode ser atribuída ao fato de área de reserva legal geralmente não estar presente nos locais efetivamente necessários para a conservação ambiental como encostas, topo de morros e margens dos cursos d'água, e, portanto, não trazerem os benefícios para a redução da erosão, assoreamento e provisão de recursos hídricos. Ademais, a reserva legal compete diretamente por área com a agropecuária nas propriedades (CARNEIRO, 2001). Assim, a níveis muito baixos de área ocupada com a reserva legal, aumentos na área de reserva legal estariam associados a uma diminuição do preço por hectare da terra, dado que uma maior área de reserva legal implica em menor área disponível para a agropecuária.

Pelas estimativas, a área agricultável das fazendas, representada pelo número de tratores por hectare, apresenta grande importância sobre o valor da terra, de forma que o aumento em um trator por hectare eleva em cerca de $\mathrm{R} \$ 400$ $\mathrm{mil} / \mathrm{ha}$ o preço da terra. Deve-se ressaltar que a variação do número de tratores por hectare ocorre em escala decimal e que a média do número de tratores por hectare é relativamente baixa. A existência de custos de transação significativos foi confirmada, uma vez que a redução na área média dos municípios (das propriedades) em um hectare eleva o preço da terra em $\mathrm{R} \$ 3,70 / \mathrm{ha}$. A disponibilidade de água também se mostrou significativa, sendo que um aumento de 0,01 no número de recursos hídricos sobre número de estabelecimentos por município eleva o preço médio do hectare em cerca de $\mathrm{R} \$ 14,50$. A lavoura permanente apresentou preço implícito de cerca de $\mathrm{R} \$ 88,00 /$ ha. Isso é devido à lavoura formada apresentar rendas futuras que serão apropriadas pelo comprador. Por fim, o aumento da densidade demográfica do município em uma unidade está associado a um aumento do valor do hectare em $R \$ 3,00$. 


\section{CONSIDERAÇÕES FINAIS}

A importância dos recursos naturais e sua conservação em Minas Gerais puderam ser determinadas e valoradas neste estudo, confirmando aspectos importantes como a importância das práticas de conservação e despertando a atenção não somente para a necessidade da execução destas, mas pela correta execução, dada a relação encontrada para a rotação de culturas, que muito provavelmente se deve à execução inadequada ou baixo nível de utilização, inferior ao necessário para que uma melhora e, ou conservação do solo seja alcançada.

Este trabalho também traz contribuições importantes para avaliar a política florestal brasileira. Para Minas Gerais, as áreas de preservação permanente não se mostraram associadas ao preço da terra, e, portanto, não se pôde analisar o impacto dessa exigência legal sobre a agricultura. As áreas de reserva legal, por seu turno, apresentaram associação negativa e significativa ao preço do hectare de terra, ou seja, um maior percentual de área nos estabelecimentos agropecuários ocupada com mata destinada à reserva legal estaria associado a menores valores da terra. Ademais, a contribuição marginal da área de mata para o preço da terra foi negativa no ponto médio da amostra, demonstrando que o produtor está assumindo o custo de manter a área de floresta.

\section{REFERÊNCIAS}

ANSELIN, L.; LOZANO-GRACIA, N. Spatial hedonic models. Arizona State University GeoDa Center for Geospatial Analysis and Computation. Working Paper, n. 2, 2008.

ARRAIZ, I.; DRUKKER, D. M.; KELEJIAN, H. H.; PRUCHA, I. R. A Spatial Cliff-Ord-type model with heteroscedastic innovations: small and large sample results. Journal of Regional Science, v. 50, n. 2, p. 592-614, 2012

BIVAND, R. Spatial dependence: weighting schemes, statistics and models. $\mathbf{R}$ Documentation. Disponível em: http://cran.r-project.org/web/packages/spdep/ spdep.pdf. Acesso em: 10 nov. 2010. 
BREUSH, T.; PAGAN, A. A simple test for heteroscedasticity and random coefficient variation. Econometrica, v. 47, n. 5, p. 1287-1294, 1979.

CARNEIRO, S. L. Estudo prospectivo da implantação da reserva legal em propriedades rurais familiares representativas de sistemas de produção de grãos na região de Londrina - estado do Paraná. 2005. 209f. (Master of Science) - Administração, Universidade Estadual de Londrina e Universidade Estadual de Maringá, Londrina.

CARNEIRO, P. A. S.; FONTES, M. P. F.; FONTES, R. Índice pedológico e de Manejo de Solos como Suporte ao Estudo das Disparidades Microrregionais em Minas Gerais. In: FONTES, R; FONTES, M. P. F. Crescimento e Desigualdade Regional em Minas Gerais. Viçosa: Editora: Folha de Viçosa, 2005, p. 249 - 292.

CRAIG, L. A.; PALMQUIST, R. B.; WEISS, T. Transportation improvements and land values in the antebellum United States: a hedonic approach. Journal of Real Estate Finance and Economics, v. 16, n. 2, p. 173-189, 1998.

CROPPER, M. L.; DECK, L. B.; MCCONNELL, K. E. On the choice of functional form for hedonic price functions. The Review of Economics and Statistics, v. 70, n. 4, p. 668-675, 1988.

DE JANVRY, A.; JEAN-PHILIPPE, P.; GORDILLO, G.; SADOULET, E. Access to Land and Land policy Reforms. In: Access to Land, Rural Poverty, and Public Action. New York: Oxford University Press, 2001, p. 1-28.

FLORAX, R. J. G. M.; FOLMER, H.; REY, S. J. Specification searches in spatial econometrics: the relevance of Hendry's methodology. Regional Science and Urban Economics, v. 33, n. 5, p.557-579, 2003.

GeoMINAS - Geoprocessamento em Minas Gerais. Kit desktop mapping Versão 2.0 Disponível em: http://www.geominas.mg.gov.br/. Acesso em: 20 nov. 2010. 
GUJARATI, D. Econometria Básica. 4. ed. Rio de Janeiro: Elsevier, 2006, 812p.

iBge - instituto brasileiro de GeOgrafia e estatística. Censo Agropecuário 2006. Disponível em: http://www.sidra.ibge.gov.br/bda/pesquisas/ca/ default.asp? $\mathrm{z}=\mathrm{p} \& \mathrm{o}=2$. Acesso em: 10 fev. 2011a.

ibGe - instituto brasileiro de Geografia E estatística. Censo Demográfico 2010. Disponível em: http://www.ibge.gov.br/servidor_arquivos_est/. Acesso em: 29 fev. 2011b.

IBGE - INSTITUTO BRASILEIRO DE GEOGRAFIA E ESTATÍSTICA. Cidades@. Disponível em: http:/www.ibge.gov.br/cidadesat/ufs/download/mg_mapa_e_ municipios.pdf. Acesso em: 31 jan. 2011c.

KELEJIAN, H. H.; PRUNCHA, I. R. Specification estimation spatial autoregressive models autoregressive heteroskedastic disturbances. Journal of Econometrics, v. 157, n. 1, p. 53-67, 2010.

LEGGETT, C. G.; BOCKSTAEL, N. E. Evidence of the effects of water quality on residential land prices. Journal of Environmental Economics and Management, v. 39, n. 2, p. 121-144, 2000.

LE GOFFE, P. Hedonic pricing of agriculture and forestry externalities. Environmental and Resource Economics, v. 15, n. 4, p. 397-401, 2000.

LICHTENBERG, E.; SHORTLE, J.; WILEN, D.; ZILBERMAN, D. Natural resource economics and conservation: Contributions of agricultural economics and agricultural economists. American Journal of Agricultural Economics, v. 92, n. 2, p. 469-486, 2010.

MADDISON, D. A hedonic analysis of agricultural land prices in England and Wales. European Review of Agricultural Economics, v. 27, n. 4, p. 519-532, 2000. 
MALLIOS, Z.; PAPAGEORGIOU, A.; LATINOPOULOS, D.; LATINOPOULOS, P. Spatial hedonic pricing models for valuation of irrigation water. Global NEST Journal, v. 11, n. 4, p. 575-582, 2009.

MCCONNELL, K. E. An economic model of soil conservation. American Journal of Agricultural Economics, v. 65, n. 1, p. 83-89, 1983.

MCCONNELL, V.; WALLS, M. The value of open space: Evidence from studies of nonmarket benefits. Washington: Resources for the Future, 2005.78 p.

MMA - Ministério do Meio Ambiente. Download de dados geográficos. Disponível em: http://mapas.mma.gov.br/i3geo/datadownload.htm. Acesso em: 20 nov. 2010.

PALMQUIST, R. B.; DANIELSON, L. E. A hedonic study of the effects of erosion control and drainage on farmland values. American Journal of Agricultural Economics, n. 71, n. 1, p. 55-62, 1989.

PIRAS, G. Spatial Models with heteroskedastic innovations. R Documentation. Disponível em: cran.r-project.org/web/packages/sphet/sphet.pdf. Acesso em: 10 nov. 2010a.

PIRAS, G. Sphet: Spatial models with heteroskedastic innovations in R. Journal of Statistical Software, v. 35, n. 1, p. 1-21, 2010b.

RIGONNATO, C. A. Quem paga a conta? Subsídios e reserva legal: avaliando o custo de oportunidade do uso do solo. 2006. 106 f. Dissertação (Gestão Econômica do Meio Ambiente) - Universidade de Brasília, 2006.

ROSEN, S. Hedonic prices and implicit markets: product differentiation in pure competition. The Journal of Political Economy, v. 82, n. 1, p. 34-55, 1974. 
TÜRKER, M. F.; ÖZTÜRK, A.; PAK, M. Examination of the externality concept from the Turkish forest resources and forestry points of view. XII World Forestry Congress, Congress Proceedings, A-Forests For People, SectionA2b, Paper number 0409, Quebec City, Canada. 2003.

Recebido em: 09/03/2016

Aceito em: 06/06/2018 